1925), he directed attention to the emphasis placed on descriptive geometry, especially on general topics of transformation such as orthogonal and point projection and perspective.

The proceedings of the second day opened with a discussion on the teaching of astronomy. Mr. J. A. Edgar outlined the work which might be done with boys up to lower sixth form level and gave valuable suggestions for practical work in constructing star maps, plotting the plane of the ecliptic and the measurement of time. Mr. R. L. Marshall directed attention to some dangers which, in his opinion, might attend the addition of astronomy to the curriculum, while Dr. L. E. Lefèvre urged the claims of astrophysics in the work done by science specialists, referring especially to the various results obtained by spectrum analysis. In the ensuing discussion, Mr. W. F. Bushell mentioned the importance of the alliance between geography and astronomy.

Dr. R. R. Kuczynski read a paper on "Population Trends". He explained that, while an adequate device for the measurement of mortality has long been known, a good method of measuring fertility has only recently been evolved. $\mathrm{He}$ showed how these two measures can be combined to give the 'reproduction-rate' of a population. He stated that if fertility and mortality remain as at present, the population of western and northern Europe appears likely to drop from 194 to 150 millions by the end of the century. The U.S.S.R. is apparently an exception, and the figures here suggest an increase from 175 to 650 millions. He concluded by warning his audience that a very clear distinction should be drawn between estimates meant as forecasts and estimates meant to show what, on certain definite assumptions, the population trend would be. The figures given were to be taken as belonging to the second of these categories.

Mr. R. M. Gabriel, in the next paper, urged the inclusion of the history of mathematics in the course of study both of schools and universities. Of the different methods of presenting the history of the subject, he preferred that which dealt with the history of various topics as they occur in mathematical work. He pointed out how the history of the subject serves to throw a light on the character of times and men (for example, Cardan and Tartaglia in relation to the Renaissance ; Newton in relation to the seventeenth century). $\mathrm{He}$ instanced several mathematical types in which a knowledge of mathematical history would assist both teacher and pupil In the course of a useful discussion, Sir Thomas Heath, Mr. A. W. Siddons, Prof. E. H. Neville, Mr. M. Black and Mr. G. L. Parsons offered additional suggestions with regard to topics and bibliography.

In the afternoon, Dr. A. C. Aitken read a paper on "Arithmetical Recreations". He stated that his observations were really concerned with approxima. tion, which will assume greater importance as mechanical devices for calculation are developed. After a preliminary discussion of the mental equip. ment needed by a good computer, Dr. Aitken demonstrated rapid methods of division and squaring, and as an illustration of his methods, squared several numbers of three and four digits mentally with great rapidity. He next showed how the periods of recurr. ing decimals can be determined. These methods of approximate evaluation of a square root were con. sidered and their relative errors dismissed. Dr. Aitken concluded with some remarks on the nature of memory, in which he stressed the rhythmic element, illustrating this by writing down from memory the first two hundred figures in the value of $\pi$.

The concluding paper was given by Mr. A. Romney Green on "Geometrical Design". He commenced by describing the construction of certain polar curves and showed how these curves can be used for vases, brackets and other articles capable of being made in the school workshop. He also directed attention to the close conformity with Nature exhibited by certain leaf-designs derived from these curves. He next referred to the use of the conic (drawn as an envelope) and pointed out the superiority of these curves (used in Greek mouldings) over the circular mouldings in general use. The paper was illustrated by slides, including illustrations of pieces of furniture designed by the anthor.

In consequence of the indisposition of the president, Mr. A. W. Siddons presided over the meetings on the second day. The meetings were well attended throughout, and the usual publishers exhibition was held. A full account of the various papers will appear in the Mathematical Gazette.

\title{
Mechanized Farming*
}

\section{OXFORD CONFERENCE}

$\mathrm{T}$ HE second Conference on Mechanized Farming was held in Rhodes House, Oxford, on January $5-8$, under the auspices of the agricultural departments of the University, and attracted about 350 visitors.

The opening papers dealt with agricultural and technical problems arising from the extended use of tractors. An important technical problem arises from the use of paraffin rather than petrol as fuel. Under ordinary agricultural conditions, the use of the heavier fuel frequently results in rapid deteriora-

* Papers can be obtained from the Institute for Research in Agricultural Engineering, University of Oxford, 1s. 6d. post paid. A supplement embodying the informal discussions is to be published at a later date. tion of lubricating oil, due to its dilution with un. burned fuel components. In practice, therefore, the immediate economies which result from the use of paraffin are liable to be offset by increased consump. tion of lubricating oil, or, since farmers generally do not change the diluted oil often enough, by rapid wear of the engine. Measurements on tractors in the field and on test show that the solution of the difficulty is to maintain the temperature of the cooling water at as near boiling point as is practicable, to avoid changing over from the starting petrol to paraffin until a sufficiently high engine temperature has been reached, and to load the tractor as fully as possible. 
Another group of papers was concerned with cultivation problems. Mechanization offers so many opportunities of simplifying the traditional routine of cultivation, for example, by the use of rotary cultivators or trains of implements, that it becomes important to examine scientifically both the traditional treatments and the newer technique which may supplement them. Two papers described the work which is being done with this object at Rothamsted and Cambridge. It was suggested that certain tillage operations which are traditionally supposed to conserve soil moisture cannot be expected, in the light of modern theories of soil water movement, to exercise much direct control, although they may conserve soil moisture indirectly by removing the competition of weeds. Again, in statistical field experiments the ultimate effects of tillage operations on crop yields are frequently insignificant, although well-marked effects in soil structure can be demonstrated, for example, by the use of an instrument which automatically records the resistance to the penetration of the soil by a steel probe. Both papers concluded that traditional methods are liable to include many operations the utility of which is doubtful. This conclusion was criticized in another paper written from the farmer's point of view. It was suggested that the mental attitude of the experimenter towards cultivation operations is often at fault: that to regard the ultimate yield in a statistical experiment as the sole criterion is misleading: and that modern experimental technique is too rigid for the study of what may be considered as still an art.

Another paper opened a discussion on the maintenance of fertility, with particular reference to the part played by organic manures. It was suggested that the function of organic matter might appear less important as the science of tillage is developed and more is known about the application of such elements as boron, manganese and zinc. On the other hand, a better understanding of the part played by auxins, animal hormones and plant toxins might lead to a contrary conclusion.

Considerable interest was also aroused by several papers on grass-drying. These, however, were concerned more with questions arising from fitting the new process into farming routine than with drying technique.

Other subjects which received consideration at the Conference were equipment enabling tractors to be used for row crop work and recent developments in combine harvesting.

\section{Science News a Century Ago}

\section{The Analysis of Organic Compounds}

"Aт a meeting of the Medico-Botanical Society held on January 25, 1837, Mr. Everett made some observa. tions on the essential oil of almonds, the result of the examination of which by different continental chemists, led to the hope that the mathematical accuracy impressed upon inorganic compounds would soon be developed in organic compounds. In the analysis of almonds, a substance called amygdaline was produced. From this substance the German chemists have produced a liquid hydruet of benzoin, which by contact of atmospheric air, produces benzoic acid. With this discovery, M. Berzelius was so pleased as to suggest to MM. Dumas and Leveque (to whom the scientific world is indebted for this information) to give it a name signifying 'Dawn of Day' or 'Orb of Day', illustrative of the new era which it opened in organic chemistry. M. Mitscherlich, of Berlin, has also by the distillation of benzoic acid with quicklime, obtained an oily fluid identical with that procured in the condensation of oil gas, and described by Faraday as a liquid bi-carburetted hydrogen."(Athenceum.)

\section{Structure of the Brain in Marsupial Animals}

ON January 26, 1837, Richard Owen, Hunterian professor of anatomy to the Royal College of Surgeons, read a paper to the Royal Society "On the Structure of the Brain in Marsupial Animals". The official abstract of the paper said : "The author describes a remarkable modification in the commissural apparatus, apparently provided with a view to establish communication between the cerebral hemispheres, which he has observed in the brains of marsupial animals and which has hitherto been regarded as constituting the essential difference between the brains of oviparous and mammiferous vertebrata. . . . On comparing the structure of the brain in the Beaver and in the Wombat, he finds that the corpus callosum, or great commissure which unites the supraventricular masses of the hemispheres in the former, as well as in all other placentally developed mammalia, and which exist in addition to the fornix, or hippocampal commissure, is wholly absent in the latter animal : and that a similar deficiency exists in the brain of the Great and Bush Kangaroos, of the Vulpine Phalanger, of the Ursine and Mange's Dasyrus, and of the Virginian Opposum. . . ."

\section{Cultivation of Rice in England}

The Athenceum of January 28, 1837, records the attempts of Mr. Anderson, the curator of the Apothecaries Garden at Chelsea, to cultivate mountain rice from Nepal, the experiment having been made to see whether it could be grown in Great Britain as an agricultural crop. The seed was sown in March in a hot-house and soon germinated. In May, when the seedlings were removed to the greenhouse, they had become stout healthy plants. At the end of June, they were transferred to a sheltered place in a basin for aquatic plants, having nine inches of water and twelve inches of mud. They grew and promised well until the beginning of August, but the weather becoming cool they all sickened and died without flowering.

\section{Medical Literature in 1836}

"During the year 1836 there were published in France alone upwards of 300 volumes on the various branches of medical science. These 300 volumes, added to the numerous brochures, memoirs and other smaller tracts which have appeared, raise the quantity to 115,000 pages, which together with the journals and theses brought out at the same time render the total about 180,000 pages. Now should there be found a reader intrepid enough to undertake the perusal of all this, his monthly task must be to wade through nearly 16,000 pages, and his daily performance must be on the average 500 . So much for French medical literature merely; add English, American, German, etc. !'--(London Medical Gazette, January 28, 1837.) 